Revista Española de Antropología Americana ISSN: 0556-6533

https://doi.org/10.5209/REAA.61970

\title{
Análisis de la tecnología lítica del sitio Cueva Maripe (Santa Cruz, Argentina)
}

\author{
Darío O. Hermo ${ }^{1}$ y Virginia Lynch ${ }^{2}$
}

Recibido: 23 de febrero de 2016 / Aceptado: 4 de diciembre de 2016

Resumen. En este trabajo se analizan los conjuntos líticos del sitio Cueva Maripe, ubicado en el Macizo del Deseado (Prov. de Santa Cruz, Argentina), donde se registraron ocupaciones desde ca. 9500 hasta $c a$. 1000 años radiocarbónicos AP. Se indaga acerca de las estrategias de producción lítica asociadas a los diferentes períodos de ocupación identificados en la cueva, que corresponden a distintos momentos del Holoceno. Para ello se realizaron análisis tecno-morfológicos de los productos de talla, principalmente en relación al uso de las materias primas y al diseño artefactual. Los resultados obtenidos evidencian ciertas diferencias en relación a estos tópicos para los distintos bloques temporales registrados en Cueva Maripe. Ello ha permitido profundizar y ampliar el conocimiento acerca de estas ocupaciones e indirectamente de la relación que estos grupos cazadores-recolectores tenían con su entorno.

Palabras clave: materias primas líticas, Patagonia, cazadores-recolectores.

\section{[en] Lithic Technology Analysis at Cueva Maripe Site (Santa Cruz,} Argentina)

\begin{abstract}
Lithic production strategies involve choices linked to the procurement and processing of rocks. These strategies respond to social and environmental variables which can be studied through the artifacts. This paper analyzes the Cueva Maripe site, located in the Central plateau of Santa Cruz (Argentina) in which occupations were recorded from $c a$. 9500 to $c a$. 1000 years BP. Much of the previously analyzed lithic material corresponds to the mid Holocene. This paper updates the already existing data with those obtained in a recent field work in order to integrate the information of the lithic assemblages recovered at Cueva Maripe site. From this analysis different production strategies for the occupation periods identified at the cave are proposed. The obtained results allowed expand our knowledge about the human occupations at Cueva Maripe site and the relationship that these groups of hunter-gatherers had with their environment.
\end{abstract}

Keywords: Lithic raw materials, Patagonia, hunter-gatherers.

Sumario. 1. Introducción. 2. Sitio de estudio. 3. Materiales y metodología. 4. Resultados. 5. Discusión y conclusiones. 6. Referencias.

1 CONICET - División Arqueología, Facultad de Ciencias Naturales y Museo, Universidad Nacional de La Plata. dhermo@fcnym.unlp.edu.ar

2 CONICET - División Arqueología, Facultad de Ciencias Naturales y Museo, Universidad Nacional de La Plata. lynchvirginia@gmail.com 


\section{Introducción}

Patagonia es una de las regiones del Cono Sur en la que, durante los períodos de mejoramiento climático, los grupos humanos se dispersaron colonizando nuevos territorios, a partir de una exploración posiblemente lenta y discontinua (Borrero 1999; Borrero et al. 1998; Miotti y Salemme 2004). Hacia el Holoceno Temprano, entre los 8.5 y $7.5 \mathrm{Ka}^{14} \mathrm{C}$ AP, los mejoramientos en las condiciones climáticas globales permitieron la conformación de ambientes propicios para ser aprovechados de manera más favorable por las poblaciones humanas (Mancini et al. 2013). Estas mejoras coincidirían con el incremento en la cantidad de sitios arqueológicos fechados para este período (véase Miotti y Salemme 2004; Salemme y Miotti 2008).

En este sentido, el Macizo del Deseado es un escenario privilegiado para indagar acerca del poblamiento de Patagonia, debido a que en esta provincia geológica las evidencias de ocupaciones humanas durante la transición Pleistoceno-Holoceno y Holoceno Temprano son relativamente numerosas. En los sitios Los Toldos (Cardich et al. 1973; Miotti 1998), Piedra Museo (Miotti 1995; Miotti et al. 1999), El Ceibo (Mansur-Franchomme 1983; Cardich 1987), Cerro Tres Tetas (Paunero 2003), Cueva Casa del Minero (Paunero 2003), La Mesada (Skarbun 2011), La Martita (Aguerre 2003), El Verano (Durán et al. 2003) y La Gruta (Franco et al. 2012), han sido registradas ocupaciones tempranas, y en varios de estos sitios los conjuntos líticos estuvieron caracterizados por la presencia de artefactos elaborados sobre lascas grandes, formatizados mediante retoque marginal. La tecnología de puntas de proyectil presenta mejor definición hacia el Holoceno Temprano, lapso para el que se registran en las ocupaciones más tempranas de $c a .10 .000$ años AP, puntas cola de pescado, como en el caso de Piedra Museo (Miotti 1995); mientras que las puntas triangulares apedunculadas en los sitios arqueológicos de Los Toldos (Cardich et al. 1973), La Martita (Aguerre 2003) y El Verano (Durán 1990; Durán et al. 2003) datan de una cronología posterior de $c a .9 .000$ años AP.

Durante el Holoceno Medio (8.5-3.5 $\mathrm{Ka}^{14} \mathrm{C}$ AP) se produjo la expansión de la estepa arbustiva, en el área de Los Toldos, atribuible a condiciones climáticas de aumento de temperaturas y disminución de la humedad (Páez et al. 1999; Miotti y Salemme 2004; Mancini et al. 2013). Los fechados radiocarbónicos para este lapso son escasos tanto para el Macizo del Deseado (Hermo y Magnin 2012) como para otras regiones del país (véase listado de los mismos en Zárate et al. 2000). La tecnología de los conjuntos del Holoceno Medio de la región muestra una preponderancia en la producción de hojas y su uso como formas base, la ausencia de registro de puntas de proyectil y la aparición de bolas de boleadora (véase discusión en Hermo y Magnín 2012; Lynch y Hermo 2015). Otras evidencias materiales destacables son la presencia de valvas de moluscos marinos en el Macizo del Deseado (200 km aproximadamente en línea recta), al igual que de materia prima alóctona (obsidiana) proveniente del sector cordillerano andino (Cardich et al. 1994; Stern 1999; Miotti 2006; Miotti y Salemme 2004; Hermo 2009; Hermo y Miotti 2011).

Hacia fines del Holoceno medio se habría producido el proceso de consolidación territorial de los grupos humanos en el sector, caracterizado por alianzas e intercambios con una alta movilidad, viéndose favorecido por mayor disponibilidad de microambientes (Miotti 2006, 2012; Miotti y Salemme 1999). A medida que se fue desarrollando este proceso de consolidación, sumado a un incremento poblacional, muchos sectores nuevos habrían sido ocupados hacia el Holoceno tardío (véase Bo- 
rrero 1994-95; Goñi 2010; Cassiodoro et al. 2013), continuando, asimismo, la utilización de las cuevas y aleros como loci para diferentes actividades dentro del Macizo del Deseado (Miotti 2006). Para este lapso se han propuesto algunos cambios en los conjuntos líticos, tales como la aparición de puntas triangulares con pedúnculo y aletas, y una tendencia hacia la reducción de tamaño y del módulo de longitudanchura de las hojas y de los instrumentos elaborados sobre hojas (i.e. raspadores) (Orquera 1984-85; Aschero 1987).

A partir de estos antecedentes, el siguiente trabajo tiene por objetivo identificar los cambios en la producción de la tecnología lítica a lo largo de las diferentes ocupaciones registradas en la Cámara Norte del sitio arqueológico Cueva Maripe (Prov. de Santa Cruz, Argentina). Este sitio multicomponente, presenta una amplia profundidad temporal y recurrencia ocupacional, que lo posicionan como un interesante caso de estudio de los cambios tecnológicos a través del tiempo. En este sentido, se plantea indagar acerca de las estrategias tecnológicas de producción y evaluar si existen tendencias temporales en las tecnologías líticas desarrolladas y en las materias primas empleadas.

Por lo tanto, teniendo en consideración los modelos de poblamiento propuestos para el área de estudio (Borrero 1994-95; Borrero y Franco 1997; Miotti y Salemme 2004), se espera para las ocupaciones más tempranas de la cueva, un número reducido de artefactos líticos elaborados principalmente a partir de materias primas locales e inmediatamente disponibles, con diseños versátiles capaces de afrontar los requerimientos necesarios durante estos primeros momentos de ocupación. Para el Holoceno medio y tardío con un incremento en el número de individuos y una mayor interacción social, sería esperable que la cantidad de artefactos recuperados se incremente, al igual que el uso de materias primas alóctonas; sumado a la producción de diseños que evidencien cierta especialización funcional.

\section{Sitio de estudio}

Cueva Maripe (Figura 1) es un abrigo rocoso ubicado sobre el curso medio del cañadón La Primavera (Prov. de Santa Cruz, Argentina), en las cabeceras del Zanjón Blanco. En este cañadón se han registrado varios sitios y concentraciones, entre los que se destaca Cueva Maripe por ser el de mayor tamaño y complejidad en su estructura (Miotti et al. 2007). Hasta el momento han sido excavados $34 \mathrm{~m}^{2}$ alcanzando la roca de caja a $2 \mathrm{~m}$. de profundidad. La Cueva se encuentra dividida internamente en dos cámaras, Norte y Sur, donde han podido discriminarse diversos momentos de ocupación (desde la transición Pleistoceno-Holoceno hasta Holoceno tardío), (ver Miotti et al. 2014; Mosquera 2014).

La secuencia cultural indica una alta redundancia ocupacional, evidenciada a partir de la presencia de abundantes restos materiales (artefactos líticos y óseos, restos faunísticos y vegetales, arte mobiliar y pigmentos) y es por esto mismo que ha sido considerado un sitio de uso principalmente residencial (Miotti et al. 2007; Hermo 2008; Lynch 2013, 2014; Marchionni 2013).

En este trabajo, nos centramos en la cámara norte de Cueva Maripe, donde se han discriminado 6 capas estratigráficas, 4 de las cuales presentan material arqueológico (Miotti et al. 2014) (Figura 1). 

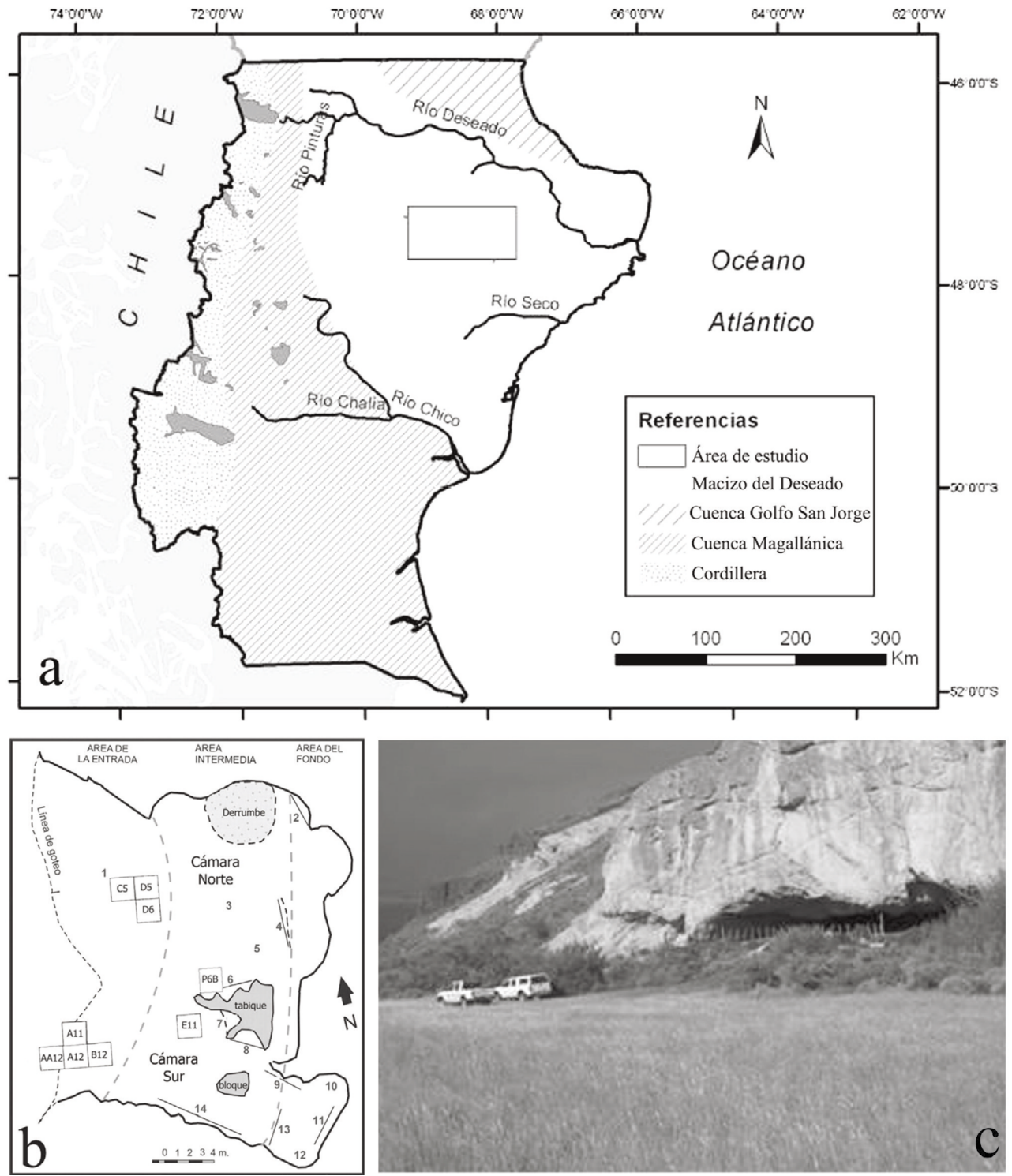

Figura 1. Cueva Maripe: a) Localización del sitio arqueológico; b) dibujo en planta del sitio estudiado; c) foto del sitio tomada en los inicios de las excavaciones.

Así, los conjuntos de capa 5 de Cámara Norte corresponden a ocupaciones del Holoceno temprano, entre ca. 9200 y 7200 años radiocarbónicos AP. Sin embargo, del sector sur se obtuvo un fechado de $c a$. 9500 años AP, por lo que se otorgó una asignación temporal de ocupación en la cueva desde la transición PleistocenoHoloceno (Miotti et al. 2014). Aun así, no se registraron restos de megamamíferos pleistocénicos, siendo el guanaco (Lama guanicoe) el principal recurso faunístico explotado (Marchionni 2013). 
Las ocupaciones de la capa 4 fueron datadas en el Holoceno medio, $c a$. $5400 \mathrm{y}$ 3500 años AP (Miotti et al. 2014). Los restos de fauna corresponden principalmente al guanaco, pero se propuso un uso complementario de Rheidae, basado en la presencia de fragmentos de cáscaras de huevo (Marchionni 2013).

Finalmente, los elementos que integran las capas 2 y 3 (en adelante capa 2/3), corresponden al Holoceno tardío (ver Miotti et al. 2014) y el guanaco continua siendo la evidencia faunística con mayor representación (Marchionni 2013).

\section{Materiales y metodología}

La muestra analizada para este trabajo corresponde a los Artefactos Formatizados $(\mathrm{AF})^{3}$ y Artefactos No Formatizados $(\mathrm{ANF})^{4}$ obtenidos mediante registro tridimensional de las cuadrículas C5, D5 y D6 $\left(24 \mathrm{~m}^{2}\right)$ en la Cámara Norte de Cueva Maripe (Cuadro 1). La descripción y análisis de los materiales líticos tallados fue realizada siguiendo la propuesta descriptiva de Aschero $(1975,1983)$, Aschero y Hocsman (2004) y modificaciones sensu Hermo (2008). A su vez, se implementaron diferentes índices con el fin de comparar la variabilidad de los conjuntos. Para esto se calculó el índice de riqueza y de homogeneidad (Shannon y Weaver 1949; Zar 1974; Pielou 1977). Estos índices expresan la diversidad de los conjuntos minimizando el grado en que el tamaño de las muestras afecta las comparaciones entre ellas (Guráieb 1999; Bozzuto 2013). Para estos índices se consideró únicamente el número mínimo de desechos (sensu Aschero et al. 1993-94), es decir la suma de los artefactos enteros y los fragmentados con talón. Esto permite evitar la sobrestimación de determinadas categorías en la muestra analizada.

En el caso de los AF se aplicó los índices a las variables grupo tipológico y materia prima, mientras que, para los ANF se calculó en base a forma de lasca y materia prima identificada.

En cuanto a las materias primas, se utilizó la clasificación generada para el área, realizada a partir de estudios geológicos y petrológicos de fuentes de aprovisionamiento y de muestras arqueológicas de Cueva Maripe y otros sitios (Cattáneo 2004; Hermo 2008; Magnin 2015; Hermo et al. 2015).

\section{Resultados del análisis lítico}

La muestra analizada consta de un total de 99 Artefactos Formatizados y de $469 \mathrm{Ar}-$ tefactos No Formatizados ${ }^{5}$ de tamaños superiores a pequeño (Tamaño 1 - Bagolini 1968, en Aschero 1975). Asimismo se registraron 12 núcleos, clase tipológica que no será abordada en este trabajo debido a que fue detallada en una reciente publicación (Hermo y Lynch 2015).

\footnotetext{
3 Categoría que definen Aschero y Hocsman (2004) para los artefactos líticos tallados con filos retocados intencionalmente.

4 Categoría igualmente definida por Aschero y Hoscman (2004) pero a diferencia del anterior los filos se encuentran en estado natural.

5 Las diferencias de frecuencias en relación con trabajos anteriores (i.e. Miotti et al. 2007; Hermo 2008) se debe a los progresos en los remontajes que se han realizado en estos años.
} 
Los conjuntos de las capas 4 y 5 muestran una notoria diferencia en relación con el de las capas $2 / 3$ en cuanto a la frecuencia artefactual, ya que los materiales ubicados en las dos capas más profundas conforman poco más del $82 \%(n=466)$ de la muestra (Cuadro 1).

Cuadro 1. Frecuencias por capa según clases tipológicas

\begin{tabular}{|c|c|c|c|c|}
\hline \multirow[t]{2}{*}{ Conjunto } & \multicolumn{2}{|c|}{ AF } & \multicolumn{2}{|c|}{ ANF } \\
\hline & $\mathrm{n}$ & $\%$ & $\mathrm{n}$ & $\%$ \\
\hline Capa 2/3 & 35 & 35,4 & 63 & 13,4 \\
\hline Capa 4 & 41 & 41,4 & 174 & 37,1 \\
\hline Capa 5 & 23 & 23,2 & 232 & 49,5 \\
\hline Total & 99 & 100 & 469 & 100 \\
\hline
\end{tabular}

\subsection{Artefactos Formatizados (AF)}

El estudio de AF permitió determinar una serie de diferencias y similitudes entre los conjuntos de cada capa. En relación a la integridad artefactual podemos mencionar que únicamente en la capa 4 el mayor porcentaje corresponde a piezas enteras $(41 \%$, $\mathrm{n}=17$ ). Sin embargo, la mayoría de estas piezas se encuentran fracturadas sin talón, a excepción de la capa 2/3 (Cuadro 2).

Cuadro 2. Estado de fragmentación de los AF por capa

\begin{tabular}{|c|c|c|c|c|c|c|c|}
\hline \multirow[t]{2}{*}{ Estado } & \multicolumn{2}{|c|}{ Capa $2 / 3$} & \multicolumn{2}{|c|}{ Capa 4} & \multicolumn{2}{|c|}{ Capa 5} & \multirow[t]{2}{*}{ Total } \\
\hline & $n$ & $\%$ & $\mathrm{n}$ & $\%$ & $\mathrm{n}$ & $\%$ & \\
\hline$\overline{\mathrm{E}}$ & 11 & 31,4 & 17 & 41,4 & 7 & 30,4 & 35 \\
\hline FCT & 18 & 51,4 & 7 & 17,0 & 2 & 8,7 & 27 \\
\hline FST & 6 & 17,1 & 17 & 41,4 & 14 & 60,8 & 37 \\
\hline Total & 35 & 100 & 41 & 100 & 23 & 100 & 99 \\
\hline
\end{tabular}

Si bien se registró el estado de fragmentación, los trabajos de remontaje permitieron establecer que los elementos fracturados corresponden cada uno a diferentes artefactos, por lo que las siguientes inferencias se basan en la totalidad de la muestra de AF. Dado que la frecuencia de artefactos por capa es muy diferente, procedimos a calcular los índices de riqueza y homogeneidad (Shannon y Weaver 1949; Zar 1974; Pielou 1977), tanto para grupos tipológicos como para materias primas. Los valores obtenidos son similares para las distintas capas, con algunas excepciones:

La riqueza de materias primas es menor en la capa 5 , mientras que la capa $2 / 3$ se diferencia por tener la menor homogeneidad de rocas (Cuadro 3). Por su lado, la mayor riqueza de grupos tipológicos se observó en la capa 5, en la que los artefactos están repartidos equitativamente en las diferentes categorías utilizadas.

Cuadro 3. Índices de Riqueza y Homogeneidad en las diferentes capas identificadas

\begin{tabular}{|c|c|c|c|c|c|c|c|c|}
\hline & \multicolumn{4}{|c|}{ Materias primas } & \multicolumn{4}{|c|}{ Grupos tipológicos } \\
\hline & Capa 2/3 & Capa 4 & Capa 5 & Total & Capa 3 & Capa 4 & Capa 5 & Total \\
\hline$\overline{\text { Riqu }}$ & 0,828 & 0,887 & 0,795 & 0,863 & 0,463 & 0,521 & 0,753 & 0,637 \\
\hline Homogeneidad & 0,795 & 0,929 & 0,833 & 0,829 & 0,663 & 0,669 & 0,834 & 0,637 \\
\hline
\end{tabular}


Por lo tanto, en la capa 5 se registraron ocho de los diez grupos que conforman el total de la muestra (Cuadro 4), variando en cuanto a la longitud y conformación de sus filos. El grupo de raspadores es el más numeroso $(n=9,39,13 \%), 6$ de ellos elaborados sobre lascas, uno sobre hoja y en los dos restantes no se pudo establecer su forma base. Entre los demás grupos tipológicos se encuentran elementos unifaciales, formatizados mediante retoque marginal sobre lascas (muescas retocadas, raederas, unifaces y un cepillo). En menor medida se registraron artefactos bifaciales: cuatro fragmentos de bifaces y un fragmento de punta de proyectil triangular apedunculada (Cuadro 4).

Cuadro 4. Grupos tipológicos y estado de fragmentación por capa

\begin{tabular}{|c|c|c|c|c|c|c|c|c|}
\hline \multirow[t]{2}{*}{ Grupos Tipológicos } & \multicolumn{2}{|c|}{ Capa 2/3 } & \multicolumn{2}{|c|}{ Capa 4} & \multicolumn{2}{|c|}{ Capa 5} & \multicolumn{2}{|c|}{ Total } \\
\hline & 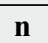 & $\%$ & $n$ & $\%$ & $n$ & $\%$ & $n$ & $\%$ \\
\hline Bifaces & 0 & 0,00 & 0 & 0,00 & 4 & 17,39 & 4 & 4,09 \\
\hline Cepillo & 0 & 0,00 & 0 & 0,00 & 1 & 4,35 & 1 & 1,01 \\
\hline FND & 5 & 14,29 & 4 & 9,76 & 1 & 4,35 & 10 & 10,10 \\
\hline Muescas retocadas & 2 & 5,71 & 0 & 0,00 & 1 & 4,35 & 3 & 3,03 \\
\hline Limaces & 0 & 0,00 & 1 & 2,44 & 0 & 0,00 & 1 & 1,01 \\
\hline Láminas retocadas & 4 & 11,43 & 4 & 9,76 & 0 & 0,00 & 8 & 8,08 \\
\hline Puntas de proyectil & 0 & 0,00 & 1 & 2,44 & 1 & 4,35 & 2 & 2,02 \\
\hline Raederas & 1 & 2,86 & 5 & 12,20 & 4 & 17,39 & 10 & 10,10 \\
\hline Raspadores & 23 & 65,71 & 26 & 63,41 & 9 & 39,13 & 58 & 58,58 \\
\hline Unifaces & 0 & 0,00 & 0 & 0,00 & 2 & 8,70 & 2 & 2,02 \\
\hline Total & 35 & 100 & 41 & 100 & 23 & 100 & 99 & 100 \\
\hline
\end{tabular}

La estructura tipológica de la capa 4 muestra algunas diferencias en relación a la anterior. Se han registrado 6 grupos tipológicos y al igual que en capa 5, el grupo de raspadores se encuentra ampliamente representado aunque en este caso con una proporción mayor (Figura 2).

Sin embargo, para estos momentos de ocupación se observa un incremento en la selección de hojas $(\mathrm{n}=19)$ como formas base alcanzando porcentajes similares a la utilización de lascas $(\mathrm{n}=21)$. La presencia de núcleos con extracciones de hojas en la capa 4 (Hermo y Lynch 2015), fue interpretada como indicador de que su manufactura habría sido llevada a cabo en el interior de la cueva, donde también han sido recuperadas hojas de aristas simples, dobles y múltiples con o sin corteza sobre su superficie (véase acápite siguiente). En cuanto a los demás grupos identificados, las raederas y láminas retocadas presentan frecuencias menores $(n=5,12 \%$ y $n=4,10 \%$ respectivamente). Las raederas han sido manufacturadas exclusivamente sobre lascas de filos simples, regularizados por retoque marginal y con un ángulo de filo entre $50^{\circ}$ y $35^{\circ}$. Para el caso de las láminas retocadas, se utilizó exclusivamente hojas en su manufactura y del mismo modo, la regularización de sus filos fue realizada a partir de retoques y microrretoques marginales.

Cabe mencionar que únicamente en esta capa fue recuperada una limace ${ }^{6}$ de tamaño mediano grande elaborada sobre una lasca indiferenciada, y al igual que en capa 5 , se registró un fragmento de punta de proyectil de morfología indiferenciada tallada sobre una roca silícea de coloración marrón.

\footnotetext{
${ }^{6}$ Instrumento lítico de espesor medio a grueso, cuyo filo es regular y extendido por el perímetro de la pieza, la que tiene dos extremos aguzados y una cara inferior plana (Aschero 1975, 1983).
} 


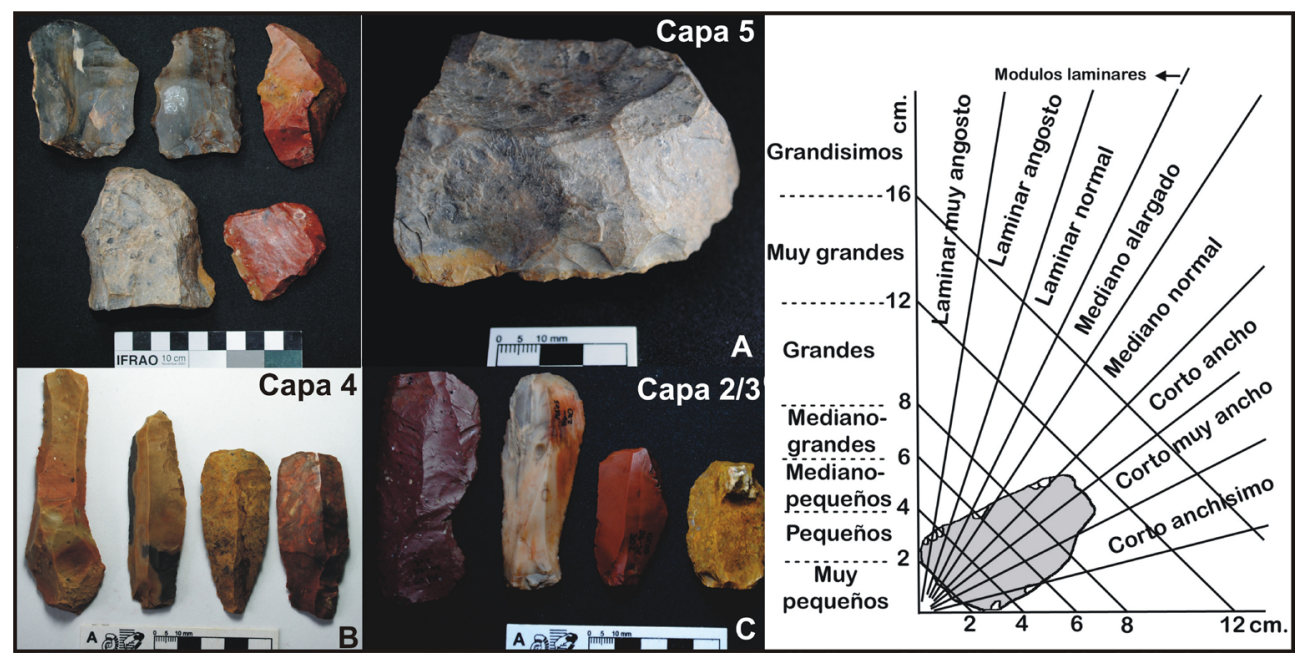

Figura 2. Materiales recuperados de las capas identificadas en la Cámara Norte.

En la capa 2/3 se identificaron 5 grupos tipológicos, donde los raspadores (sobre lascas u hojas) continúan siendo los más representados $(n=23,66 \%)$. También han sido recuperaron láminas retocadas, filos no diferenciados, muescas retocadas y una raedera elaborada sobre una lasca de arista (ver Cuadro 4).

Las materias primas utilizadas en cada capa corresponden, en su mayoría, a rocas locales inmediatamente disponibles (sensu Bayon y Flegenheimer 2004), con excepción de la obsidiana. La obsidiana negra identificada en Cueva Maripe no presenta fuentes locales conocidas y es por esta razón que su procedencia ha sido asociada al área de Pampa del Asador ( $c a .120 \mathrm{~km}$ de distancia), específicamente Cerro Pampa, fuente de dispersión más cercana al Macizo del Deseado (Stern 1999; Belardi et al. 2006). Las diferentes materias primas identificadas se encuentran representadas con frecuencias similares en los distintos momentos de ocupación dentro de la cueva. Aun así, se pueden mencionar algunas particularidades (Cuadro 5). En la capa 5, la variabilidad identificada es menor que en el resto de la secuencia (ver Cuadro 3). La utilización de materias primas de muy buena calidad como el ópalo y xilópalo se encuentran presentes con porcentajes considerables, utilizadas en la manufactura de raederas, bifaces y unifaces, instrumentos que han sido recuperados únicamente en capa 5 y de tamaños grandes y muy grandes (ver Figura 2). Por otro lado, si bien estimamos que la obtención de estas materias primas es local y procedente de una fuente secundaria de aprovisionamiento denominada LP-P1 (Hermo et al. 2015; Magnin 2015), las mismas podrían haber sido igualmente obtenidas de fuentes primarias, localizadas a una mayor distancia e identificadas en el MNBP (ca. $80 \mathrm{~km}$ de distancia en línea recta).

En las capas 4 y 2/3, la variabilidad de materias primas es similar con un leve incremento en la capa 4, donde asimismo se observa una mayor homogeneidad, es decir que los elementos recuperados se encuentran repartidos equitativamente en cada una de las categorías identificadas. El uso de la obsidiana ha sido registrado desde los primeros momentos de ocupación y probablemente haya sido obtenida mediante aprovisionamiento directo o intercambio (Hermo y Miotti 2011). Las frecuencias de 
su uso son mayores en las capas superiores, donde se observa la producción sobre esta materia prima de lascas secundarias, angulares y hojas (de aristas simples y múltiples) (Lynch 2014; Hermo y Lynch 2015).

Cuadro 5. Materias primas identificadas en los artefactos con formatización

\begin{tabular}{|c|c|c|c|c|c|c|c|c|}
\hline \multirow[t]{2}{*}{ Materia Prima } & \multicolumn{2}{|c|}{ Capa 2/3 } & \multicolumn{2}{|c|}{ Capa 4} & \multicolumn{2}{|c|}{ Capa 5} & \multicolumn{2}{|c|}{ Total } \\
\hline & $\mathbf{n}$ & $\%$ & $\mathrm{n}$ & $\%$ & $\mathbf{n}$ & $\%$ & $\mathbf{n}$ & $\%$ \\
\hline Calcedonia & 3 & 8,57 & 6 & 14,63 & 1 & 4,34 & 10 & 10,10 \\
\hline Indeterminado & 1 & 2,86 & 0 & 0,00 & 0 & 0,00 & 1 & 1,01 \\
\hline ISG1 & 14 & 40,00 & 13 & 31,70 & 9 & 39,13 & 36 & 36,36 \\
\hline ISG2 & 2 & 5,71 & 0 & 0,00 & 1 & 4,34 & 3 & 3,03 \\
\hline Obsidiana & 1 & 2,86 & 2 & 4,87 & 1 & 4,34 & 4 & 4,04 \\
\hline Ópalo & 1 & 2,86 & 2 & 4,87 & 2 & 8,69 & 5 & 5,05 \\
\hline RSG1 & 1 & 2,86 & 2 & 4,87 & 3 & 13,04 & 6 & 6,06 \\
\hline RSG2 & 5 & 14,29 & 2 & 4,87 & 1 & 4,34 & 8 & 8,08 \\
\hline RSG3 & 5 & 14,29 & 9 & 21,95 & 1 & 4,34 & 15 & 15,15 \\
\hline RSGx & 1 & 2,86 & 1 & 2,43 & 0 & 0,00 & 2 & 2,02 \\
\hline Xilópalo & 1 & 2,86 & 4 & 9,75 & 4 & 17,39 & 9 & 9,09 \\
\hline Total & 35 & 100 & 41 & 100 & 23 & 100 & 99 & 100 \\
\hline
\end{tabular}

En cuanto al tamaño de los AF enteros se observó una distribución homogénea de elementos mediano-pequeños a muy grandes en las tres capas analizadas. Sin embargo, en la capa 5 se observa una incidencia de los tamaños mayores, mientras que en las capas $2 / 3$ y 4 predominan los tamaños medianos. Al considerar los elementos fracturados se registra un leve incremento de artefactos con tamaños grandes y muy grandes en la capa 5 y cierta tendencia en la reducción de tamaños hacia los niveles superiores de ocupación (Figura 3).

Por su parte, al analizar el espesor de los AF se registra una distribución semejante, donde los elementos muy gruesos aparecen únicamente en la capa 5, al igual que un número considerable de artefactos gruesos. Mientras que en las capas superiores (4 y 2/3) se registran mayores frecuencias de artefactos delgados y muy delgados,

Figura 3. Tamaños registrados en artefactos formatizados (AF) de la Cámara Norte (E: enteros, Fr: fracturados).
Tamaño AF

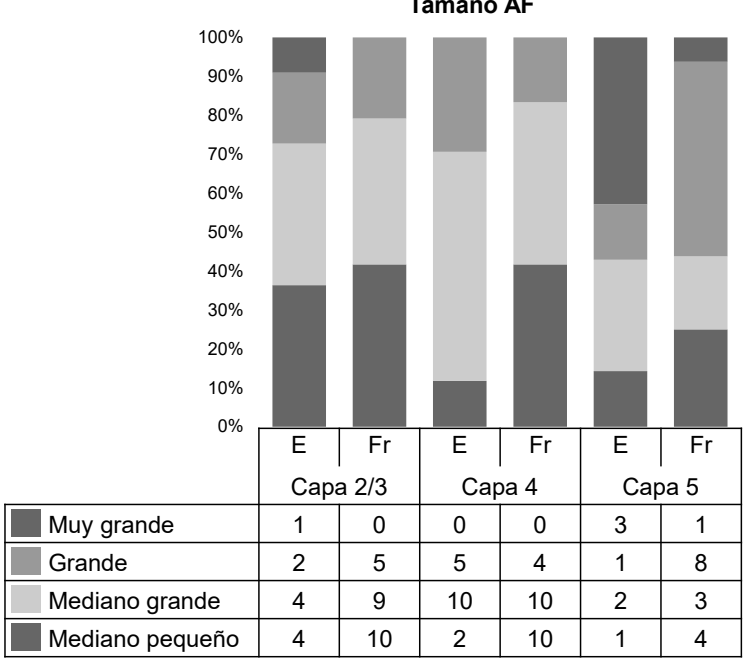




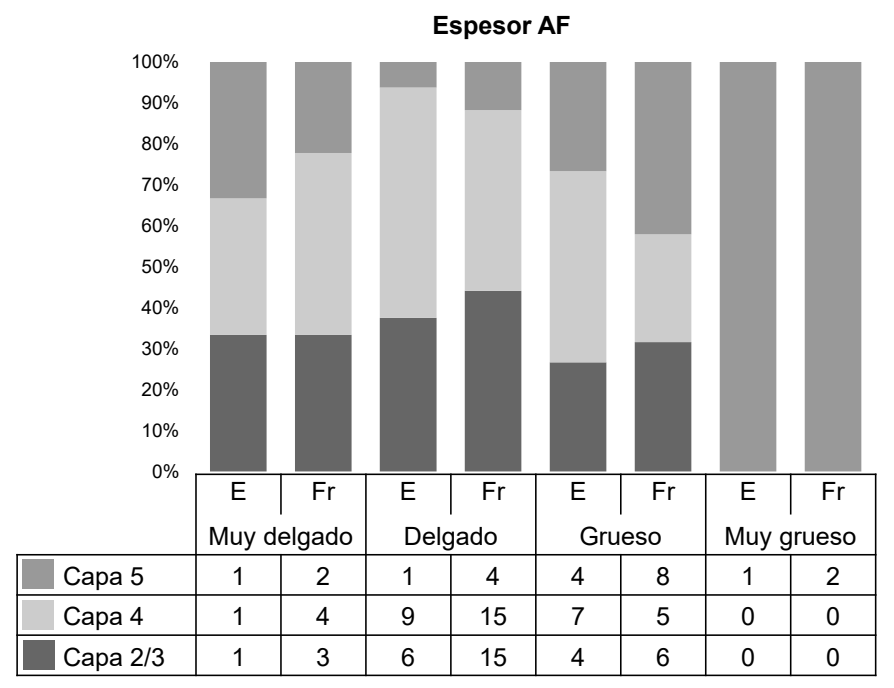

Figura 4. Espesores registrados en los artefactos formatizados (AF) de la Cámara Norte (E: enteros, Fr: fracturados).

posiblemente asociados a la selección de formas base de morfologías alargadas y relacionado a la producción de hojas, identificada en el interior de la cueva durante estos momentos de ocupación (Figura 4).

\subsection{Artefactos no formatizados (ANF)}

La muestra de artefactos no formatizados de la Cámara Norte de Cueva Maripe está constituida por 469 piezas que en su mayoría se encuentran fracturadas $(n=332$, Cuadro 6). La mayor frecuencia de artefactos enteros se registró en la capa $4(n=49,28,2 \%)$.

Cuadro 6. Estado de fragmentación de artefactos no formatizados en Cueva Maripe

\begin{tabular}{lcccccc}
\hline & Capa 2/3 & \% & Capa 4 & \% & Capa 5 & \% \\
\hline E & 22 & 34,9 & 49 & 28,2 & 45 & 19,4 \\
FCT & 18 & 28,6 & 42 & 24,1 & 67 & 28,9 \\
FST & 19 & 30,2 & 73 & 42,0 & 113 & 48,7 \\
Indet. & 4 & 6,3 & 10 & 5,7 & 7 & 3,0 \\
\hline Total & 63 & 100 & 174 & 100 & 232 & 100 \\
\hline
\end{tabular}

Los índices de riqueza y homogeneidad calculados evidencian cierta similitud entre capas, con valores altos tanto para la variabilidad de las materias primas registradas como para los tipos de lascas recuperadas (Cuadro 7).

Cuadro 7. Índices de riqueza y homogeneidad registrados en los artefactos no formatizados

\begin{tabular}{|c|c|c|c|c|c|c|c|c|}
\hline \multirow[t]{2}{*}{ ANF } & \multicolumn{4}{|c|}{ Materias primas } & \multicolumn{4}{|c|}{ Tipo de lasca } \\
\hline & Capa 2/3 & Capa 4 & Capa 5 & Total & Capa 2/3 & Capa 4 & Capa 5 & Total \\
\hline Riquez & 0,8 & 0,9 & 0,7 & 0,9 & 0,7 & 0,7 & 0,7 & 0,7 \\
\hline Homogeneidad & 0,9 & 0,8 & 0,7 & 0,8 & 0,7 & 0,8 & 0,7 & 0,7 \\
\hline
\end{tabular}

Sin embargo, la capa 5 registra los valores más bajos de riqueza y homogeneidad de materias primas del total de la secuencia. En la variable forma de lasca se observa 
una similitud con las capas superiores, a excepción de la capa 4 en la que se registra un incremento en el índice de homogeneidad, lo que permitiría plantear que en esta capa los elementos se encuentran distribuidos más equitativamente en cada una de las categorías de lascas registradas.

En el Cuadro 8 se muestran las frecuencias absolutas de la variable forma de la lasca para cada capa. En toda la secuencia dominan las formas angulares y de arista superando siempre el 50\% de los ANF enteros y fracturados con talón. En menor medida, las lascas primarias, secundarias y de dorso natural también están representadas con diferentes frecuencias en las tres capas, lo que evidencia el descortezamiento de nódulos en Cámara Norte. Una diferencia notable entre capas está dada por la presencia de hojas, cuya incidencia en la capa 5 no supera el $15 \%$, mientras que en las capas 4 y $2 / 3$ supera el $20 \%$ y $37 \%$, entre los ANF enteros y fracturados con talón.

Cuadro 8. Artefactos no formatizados recuperados de la secuencia de la Cámara Norte.

E: Enteros. FCT: Fracturados con talón. FST: Fracturados sin talón

\begin{tabular}{|c|c|c|c|c|c|c|c|c|}
\hline \multirow[t]{2}{*}{ Tipo de lasca } & \multicolumn{2}{|c|}{ Capa 2/3 } & \multicolumn{2}{|c|}{ Capa 4} & \multicolumn{2}{|c|}{ Capa 5} & \multicolumn{2}{|c|}{ Total } \\
\hline & E-FCT & FST & E-FCT & FST & E-FCT & FST & E-FCT & FST \\
\hline Primarias & 0 & 1 & 1 & 1 & 0 & 5 & 1 & 7 \\
\hline Secundarias & 1 & 1 & 2 & 5 & 8 & 10 & 11 & 16 \\
\hline Con dorso natural & 0 & 2 & 1 & 3 & 5 & 3 & 6 & 8 \\
\hline Angular & 18 & 6 & 36 & 22 & 55 & 44 & 109 & 72 \\
\hline De arista & 10 & 2 & 13 & 13 & 24 & 25 & 47 & 40 \\
\hline Plana & 1 & 0 & 3 & 3 & 1 & 0 & 5 & 3 \\
\hline Tableta de núcleo & 1 & 0 & 0 & 0 & 1 & 0 & 2 & 0 \\
\hline Hoja de arista simple & 4 & 6 & 14 & 14 & 9 & 9 & 27 & 29 \\
\hline Hoja de arista doble & 2 & 2 & 11 & 6 & 5 & 7 & 18 & 15 \\
\hline Hoja de arista múltiple & 2 & 0 & 9 & 3 & 0 & 0 & 11 & 3 \\
\hline Indeterminada & 1 & 3 & 1 & 13 & 4 & 17 & 6 & 33 \\
\hline TOTAL & 40 & 23 & 91 & 83 & 112 & 120 & 243 & 226 \\
\hline Lascas & 31 & 12 & 56 & 47 & 94 & 87 & 181 & 146 \\
\hline Hojas & 8 & 8 & 34 & 23 & 14 & 16 & 56 & 47 \\
\hline
\end{tabular}

Las materias primas presentes en los subconjuntos de ANF muestran pequeñas variaciones en la intensidad de su uso, aunque la variedad ISG1 (ignimbrita silicificada) es la roca más representada en toda la secuencia. Asimismo, en capa 5 se observa la presencia mayoritaria de otras rocas silíceas (RSG2 y ópalos) y en menor medida de xilópalo, calcedonia y RSG3. Estos tres últimos tipos de rocas son más frecuentes en las capas superiores, mientras que otras rocas (como las variedades RSG2 y RSGx) prácticamente dejan de estar representadas (Cuadro 9).

El tamaño más frecuente en las tres capas es el mediano, aunque el porcentaje de artefactos mediano-grandes se reduce hacia el final de la secuencia. Por su parte, los tamaños grandes y muy grandes también se encuentran presentes en todas las capas y alcanzan mayores proporciones en la capa 4 . Finalmente, en las capas $2 / 3$ y 4 , los ANF enteros de tamaño pequeño tienen mayor representación que en la capa 5. En este sentido, considerando que en la capa 5 las lascas muy grandes corresponden a elementos fracturados, el tamaño de estos artefactos sería aun mayor al del fragmento recuperado y, por lo tanto, evidenciaría la selección de soportes de tamaños grandes. A lo largo de toda la secuencia los ANF delgados y muy delgados están presentes entre un $70 \%$ y $80 \%$. Los bajos porcentajes de espesores gruesos y 
muy gruesos contrastan con la selección de formas para la manufactura de artefactos formatizados.

Cuadro 9. Materias primas utilizadas en la producción de ANF.

E: Enteros. FCT: Fracturados con talón. FST: Fracturados sin talón

\begin{tabular}{|c|c|c|c|c|c|c|c|c|}
\hline \multirow[t]{2}{*}{ Materia prima } & \multicolumn{2}{|c|}{ Capa2/3 } & \multicolumn{2}{|c|}{ Capa4 } & \multicolumn{2}{|c|}{ Capa5 } & \multicolumn{2}{|c|}{ Total } \\
\hline & E/FCT & FST & E/FCT & FST & E/FCT & FST & E/FCT & FST \\
\hline Basalto & 1 & 3 & 5 & 2 & 3 & 1 & 9 & 6 \\
\hline Calcedonia & 8 & 1 & 4 & 8 & 5 & 8 & 17 & 17 \\
\hline Indeterminado & 2 & 4 & 6 & 6 & 7 & 9 & 15 & 19 \\
\hline ISG1 & 11 & 7 & 34 & 47 & 59 & 64 & 104 & 118 \\
\hline ISG2 & 1 & 0 & 5 & 2 & 2 & 2 & 8 & 4 \\
\hline Obsidiana & 6 & 3 & 2 & 1 & 1 & 1 & 9 & 5 \\
\hline Ópalo & 1 & 1 & 8 & 3 & 11 & 18 & 20 & 22 \\
\hline RSG1 & 0 & 0 & 7 & 3 & 2 & 3 & 9 & 6 \\
\hline RSG2 & 2 & 0 & 2 & 0 & 14 & 8 & 18 & 8 \\
\hline RSG3 & 4 & 3 & 11 & 6 & 3 & 6 & 18 & 15 \\
\hline RSGX & 0 & 0 & 1 & 3 & 4 & 0 & 5 & 3 \\
\hline Xilópalo & 4 & 1 & 6 & 2 & 1 & 0 & 11 & 3 \\
\hline Total & 40 & 23 & 91 & 83 & 112 & 120 & 243 & 226 \\
\hline
\end{tabular}

Estas distribuciones vistas a la luz de las diferentes formas, tamaños y espesores relativos registrados entre los ANF, evidencian la diversidad en las actividades extractivas y de formatización de artefactos en las diferentes ocupaciones registradas en Cámara Norte (Figuras 5 y 6).

\section{Discusión y conclusiones}

Los resultados obtenidos nos permiten generar una serie de interpretaciones acerca de la tecnología lítica y de la utilización de las diferentes materias primas a lo largo de la secuencia ocupacional de Cámara Norte en Cueva Maripe.

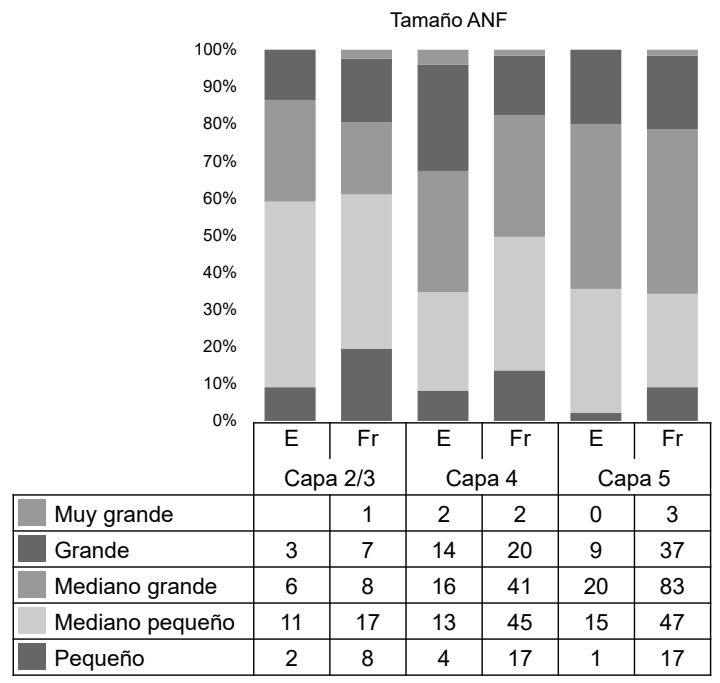

Figura 5. Tamaños registrados en artefactos no formatizados (ANF) de la Cámara Norte (E: enteros, Fr: fracturados). 
Figura 6. Espesores registrados en los artefactos no formatizados (ANF) de la Cámara Norte (E: enteros, Fr: fracturados).

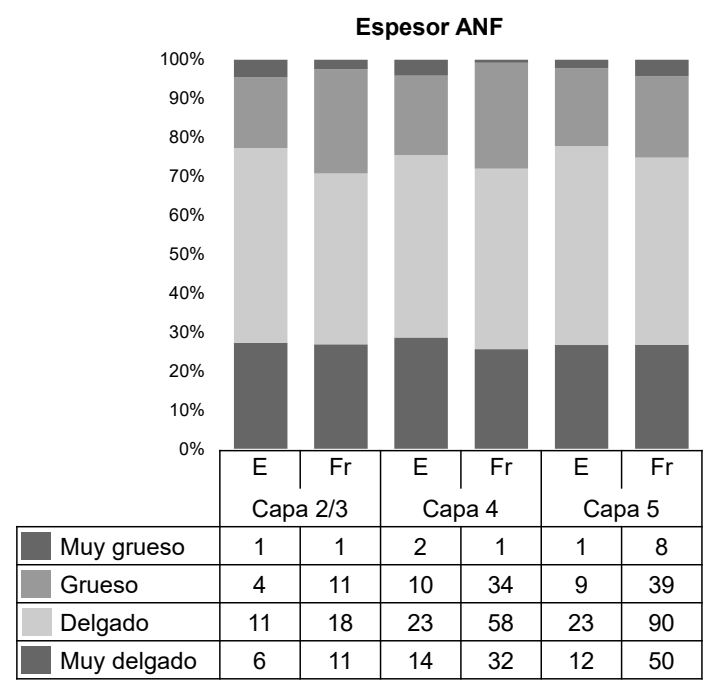

El conjunto de AF en capa 5 presenta una alta riqueza de grupos tipológicos tanto unifaciales como bifaciales, aunque con una amplia representación de los primeros, formatizados mediante retoque marginal. No obstante, se destaca que es en esta única capa en la que se registraron un cepillo, unifaces, bifaces y un fragmento de punta de proyectil triangular apedunculada. La presencia de bifaces y unifaces ha sido registrada en numerosas ocupaciones del Holoceno temprano del norte de la provincia de Santa Cruz como en Los Toldos 3, AEP1 (U4/5), El Ceibo 7, Cerro Tres Tetas 1, Casa del Minero 1, Cueva Túnel y área Río Pinturas, (Cardich y Flegenheimer 1978; Paunero y Castro 2001; Aguerre y Gradin 2003; Cattáneo 2004). La producción de estos instrumentos fue interpretada como correspondiente a diferentes etapas de la manufactura de cabezales líticos (véase Nami 2003) y, para el sector sur de Patagonia, se planteó que podrían estar relacionados con los momentos iniciales de poblamiento de la región (Belardi et al. 2010) debido a que presentan diseños confiables, versátiles y transportables -sensu Nelson 1991. Asimismo, en los contextos mencionados también se ha registrado una preferencia por la manufactura de artefactos unifaciales de tamaños grande y muy grande elaborados sobre lascas espesas.

Por otro lado, la riqueza de materias primas representada entre los AF de capa 5, es relativamente baja y abundan rocas inmediatamente disponibles (Bayón y Flegenheimer 2004). Materias primas como el xilópalo y la obsidiana se encuentran presentes en proporciones muy bajas ( $\mathrm{n}=2$ y 1 , respectivamente). En base a la información previa (Hermo 2009; Hermo et al. 2015), asumimos que las mismas proceden de distancias cercanas y/o medias (LP-P1 o Parque Nacional Bosques Petrificados $c a$. $80 \mathrm{~km}$ ) para el caso del xilópalo y de largas distancias (área de Pampa del Asador, ca. $120 \mathrm{~km}$ ) para la obsidiana.

Las formas base utilizadas, en general, han sido lascas de tamaños grandes a muy grandes y espesores gruesos a muy gruesos. Al observar estas variables entre los ANF, se destaca que los valores no son diferentes a lo largo de la secuencia, lo que estaría indicando distintas etapas de manufactura y obtención de formas base, pero con una selección preferencial de lascas grandes y espesas para la manufactura de artefactos formatizados. 
A su vez, los trabajos desarrollados anteriormente en el área (Borrero 1994-95; Borrero y Franco 1997; Franco 2002; Cattáneo 2004; Miotti y Salemme 2004; Skarbun et al. 2015), han formulado que para una etapa de exploración, los conjuntos artefactuales se encuentran caracterizados por filos largos y formas base de lascas grandes. Sin embargo, en el caso de Cueva Maripe, las frecuencias altas de raspadores no condicen con dicha expectativa. Los fechados radiocarbónicos obtenidos ubican estos eventos en $c a$. 9100 años AP, momentos en los que el área ya se encontraba poblada. Por lo tanto, planteamos que las ocupaciones iniciales de capa 5 en Cámara Norte corresponden entonces a la ampliación de los espacios de vida de los cazadores-recolectores del Holoceno temprano de Patagonia, y no es necesariamente esperable un correlato material de exploración.

A diferencia de estas primeras ocupaciones, el conjunto de AF de capa 4 presenta una riqueza relativamente baja de grupos tipológicos y una alta variabilidad en las materias primas utilizadas. Aquí los raspadores superan el $62 \%$ y se registran láminas retocadas, grupo ausente en la capa 5. Estos instrumentos muestran frecuencias mayores de utilización de hojas como formas base en comparación con la capa anterior, mientras que entre los ANF prácticamente se duplica la presencia de hojas. El análisis funcional efectuado, tanto en AF sobre hojas como en hojas con filos naturales, comprobó un uso casi exclusivo sobre materiales duros (i.e. hueso y/o madera, Lynch 2014; Lynch y Hermo 2015) y se cree que su producción no estaría vinculada a la maximización de materias primas, dado que existen numerosas fuentes de aprovisionamiento primario y secundario (cuencas) cercanas al sitio (Hermo et al. 2015); sino a un incremento en la eficacia para la obtención de diseños más versátiles y/o mantenibles (Nelson 1991) con filos de características propicias (largo y rectilíneo) para su uso sobre diferentes materiales y durezas, propuesta igualmente planteada por otros autores en la zona (Paunero et al. 2007).

A su vez en la capa 4, la reducción en volumen de los artefactos es otra de las elecciones de manufactura registradas. En cada capa, los AF y ANF enteros tienden a ser de menor tamaño, y esto no se debe al grado de reactivación de los instrumentos, sino a elecciones culturales detectadas igualmente a nivel regional (Borrero y Franco 1997; Franco 2002). La disminución del tamaño observada en el conjunto y específicamente en el grupo de raspadores podría estar relacionado al uso de dispositivos de enmangue. Los resultados del análisis funcional realizado, mostraron micropulido generado por el contacto con material duro en la porción proximal de raspadores recuperados de capa 4 , lo que estaría indicando cambios en los modos de utilización de estos instrumentos hacia el Holoceno medio (Lynch y Hermo 2015; Lynch y Miotti 2016).

En cuanto a la selección de materias primas, si bien se mantienen las rocas inmediatamente disponibles, los artefactos formatizados registran nuevas variedades de rocas (RSG2 y RSGx). Este incremento en la variabilidad de materias primas podría indicar un mayor conocimiento de los recursos líticos disponibles en el área, lo que concuerda con las expectativas para ocupaciones del Holoceno medio en la región planteadas por Miotti et al. (2015). Es importante destacar aquí que en esta capa se halló evidencia de manufactura de bolas de boleadora (Hermo 2008). Esta tecnología de armas constituye no sólo una innovación a nivel tecnológico, sino también nuevas necesidades (rocas más duras) y diferentes formas de relacionarse con el entorno (i.e. topografías específicas para emboscar a las presas). Por otro lado, el uso más frecuente de obsidiana indica el abastecimiento en otros tipos de ambientes (vg. 
región cordillerana), lo que podría haberse efectuado por aprovisionamiento directo y/o por intercambio (Miotti y Salemme 2004; Miotti 2006; Hermo y Magnin 2012). Lo mismo sucedería con el xilópalo, aunque a distancia mucho menor. Siguiendo estas consideraciones, el conjunto de la capa 4, representado por una alta densidad artefactual, respondería a ocupaciones más frecuentes de carácter residencial. Esta característica ha sido igualmente observada en otros contextos del Holoceno medio en la región (Aschero 1987; Franco 2002; Skarbun 2011). La presencia de productos de largas trayectorias implicaría, por lo tanto, un mayor conocimiento del entorno natural y social, coincidente con la consolidación territorial, proceso que se estaría gestando durante este periodo (Miotti y Salemme 2004; Miotti 2006; Goñi 2010; Skarbun 2011; Hermo y Magnin 2012; Miotti 2012; Lynch 2014; Hermo y Lynch 2015, entre otros).

Por lo tanto, las diferencias en la composición del conjunto lítico artefactual de capa 4, sumado a la presencia de boleadoras, son consonantes con los cambios tecnológicos que se registran a escala regional en este sector de Patagonia (Cardich y Flegenheimer 1978; Orquera 1984-1985; Aschero 1987; Skarbun 2011; Skarbun et al. 2015).

Finalmente, el conjunto de la capa $2 / 3$, con cronologías que incluyen finales del Holoceno medio y tardío, evidencian una mayor utilización de recursos líticos de procedencias lejanas (obsidiana y xilópalo), así como el desarrollo de actividades específicas dentro de Cámara Norte, marcado por la menor variabilidad de grupos tipológicos en toda la secuencia. Los raspadores continúan siendo los más representados (65\%), junto con las láminas retocadas (11\%), sin embargo, a diferencia de lo observado para la capa 4 , en la capa $2 / 3$ han sido utilizadas principalmente lascas con retoque unifacial. Si bien las morfologías se restringen a una pequeña cantidad de grupos tipológicos, el análisis funcional permitió inferir el uso de estos artefactos sobre diferentes materiales y durezas (madera, hueso, cuero y piel), lo que estaría indicando la manufactura de instrumentos con cierta estandarización en sus diseños pero con una baja especialización funcional (Lynch 2014; Lynch y Miotti 2016).

En cuanto a las materias primas utilizadas se mantiene la variabilidad respecto a la capa 4, con cierto incremento en el uso de algunas materias primas inmediatamente disponibles (ISG2 y RSG2). Entre los ANF se produce un descenso en la variabilidad de materias primas, pero el índice de riqueza en los tipos de lascas recuperadas es similar al de la capa 4. Estas observaciones nos inclinan a pensar en que se mantuvo el amplio conocimiento sobre la variabilidad de fuentes de materias primas disponibles en el área. La tendencia en la reducción de tamaños de los artefactos continua en los conjuntos de la capa $2 / 3$, en donde se nota una selección de formas base (de lascas u hojas) más pequeñas que en las ocupaciones previas.

Los resultados obtenidos del análisis del conjunto lítico de capa $2 / 3$, resulta coincidente con lo planteado por Miotti $(2006,2012)$ respecto a la utilización de la Cámara Norte de Cueva Maripe hacia el Holoceno tardío, como parte del proceso de expansión territorial de los grupos cazadores-recolectores (véase asimismo Borrero 1994-95; Franco 2002; Miotti y Salemme 2004; Cassiodoro et al. 2015).

En conclusión, los procedimientos y análisis presentados en este trabajo permitieron lograr ciertos avances en la comprensión de la tecnología lítica a partir de los conjuntos líticos recuperados de la Cámara Norte de Cueva Maripe. En este sentido, se ha observado una serie de cambios en la circulación y uso de materias primas a lo largo de las diferentes ocupaciones identificadas en el sitio, que en términos ge- 
nerales son coherentes con las tendencias registradas en la tecnología lítica a nivel regional.

Por lo tanto, este trabajo constituye un avance en las investigaciones sobre las prácticas tecnológicas en la región y complementa algunas de las ideas propuestas en trabajos previos (Hermo 2008; Hermo y Magnin 2012; Miotti et al. 2014; Lynch 2013, 2014; Hermo y Lynch 2015; Lynch y Hermo 2015; Lynch y Miotti 2016, entre otros).

Agradecimientos: Versiones previas de este trabajo han sido revisadas por Laura Miotti, Celeste Weitzel, Rocío Blanco y Juan Pablo Carbonelli. Nuestro agradecimiento a ellos, y a nuestros compañeros de laboratorio, por sus aportes. Damián Bozzuto colaboró desinteresadamente brindando su apoyo en cuestiones técnicas. Pese a esos esfuerzos, lo aquí escrito es de nuestra exclusiva responsabilidad. Este trabajo fue financiado mediante los subsidios PICT 0176 (ANPCyT), N/665 y PPID N003 (Universidad Nacional de La Plata).

\section{Referencias}

Aguerre, Ana Margarita

2003 «La Martita: ocupaciones de 8000 años en la Cueva 4», en Arqueología y Paleoambiente en la Patagonia Santacruceña Argentina, Ana Aguerre, Comp., pp. 29-61. Buenos Aires: Edición del autor.

Aguerre, Ana Margarita y Carlos Gradin

2003 «Dinámica poblacional, Río Pinturas y el curso medio», en Arqueología y paleoambiente en la Patagonia santacruceña argentina, Ana Aguerre, comp., pp. 153-204. Buenos Aires: Edición del autor.

AsCHERo, Carlos

1975 Ensayo para una clasificación morfológica de artefactos líticos aplicada a estudios tipológicos comparativos. Informe a CONICET. Buenos Aires. Ms.

1983 Ensayo para una clasificación morfológica de artefactos líticos. Apéndices A y B. Cátedra de Ergología y Tecnología, Universidad de Buenos Aires. Buenos Aires. Ms.

1987 «Tradiciones culturales en la Patagonia Central (una perspectiva ergológica)», en Comunicaciones: Primeras Jornadas de Arqueología de la Patagonia, pp. 17-26. Trelew: Dirección de Cultura de la Provincia de Chubut.

Aschero, Carlos y Salomón Hocsman

2004 «Revisando cuestiones tipológicas en torno a la clasificación de artefactos bifaciales», en Temas de arqueología. Análisis lítico, M. Ramos, A. Acosta y D. Loponte, comps., pp. 7-25. Luján: Universidad Nacional de Luján.

Aschero, Carlos, Liliana Manzi y Analía Gómez

1993-94 «Producción lítica y uso del espacio en el nivel 2b4 de Quebrada Seca 3». Relaciones de la Sociedad Argentina de Antropología 19: 191-214.

BAGOLINI, Bernardino

1968 «Ricerche sulle dimensioni dei manufatti litici preistorici non ritoccati». Annali dell'Universitá di Ferrara, Sezione XV (Paleontología Umana e Paletnologia) 1 (10): 195-219. 
BAYON, Cristina y Nora FLEGENHEIMER

2004 «Cambio de planes a través del tiempo para el traslado de roca en la pampa bonaerense». Estudios Atacameños 28: 59-70.

Belardi, Juan Bautista, Pedro TiBeri, Charles Stern y Alejandro SúNiCo

2006 «Al este del cerro Pampa: ampliación del área de disponibilidad de obsidiana de Pampa del Asador (Provincia de Santa Cruz)». Intersecciones en Antropología 7: 27-36.

Belardi, Juan Bautista, Silvana Espinosa, Flavia Carballo Marina, Gustavo Barrientos, Rafael GoÑI, Alejandro Súnico, Tirso Bourlot, Cecilia Pallo, Anahí Re y Patricia Campan 2010 «Las cuencas de los lagos Tar y San Martín (Santa Cruz, Argentina) y la dinámica del poblamiento humano del sur de Patagonia: integración de los primeros resultados». Magallania 38 (2):165-188.

BORRERO, Luis

1994-95 «Arqueología de la Patagonia». Palimpsesto. Revista de Arqueología 4: 9-69.

1999 «Human Dispersal and Climatic Conditions during the Late Pleistocene Times in Fuego-Patagonia». Quaternary International 53-54: 93-99.

Borrero, Luis y Nora Franco

1997 «Early Patagonian Hunters-Gatherers: Subsistence and Technology». Journal of Anthropological Research 53 (2): 219-239.

Borrero, Luis, Marcelo ZÁrate, Laura Miotti y Mauricio Massone

1998 «The Pleistocene-Holocene Transition and Human Occupations in the Southern Cone of South America». Quaternary International 49-50: 191-199.

Bozzuto, Damián

2013 «Análisis del material lítico superficial en el noreste del lago Pueyrredón-Cochrane (provincia de Santa Cruz, Argentina)». Revista Española de Antropología Americana 43 (1): 73-88.

CARDich, Augusto

1987 «Arqueología de Los Toldos y El Ceibo (provincia de Santa Cruz, Argentina)». Estudios Atacameños 8: 95-113.

CARDich, Augusto y Nora FlegenHeIMER

1978 «Descripción y tipología de las industrias más antiguas de Los Toldos». Relaciones de la Sociedad Argentina de Antropología XII: 225-242.

CARDich, Augusto, Lúcio CARDich y Adam HadjuK

1973 «Secuencia arqueológica y cronología radiocarbónica de la Cueva 3 de Los Toldos (Santa Cruz, Argentina)». Relaciones de la Sociedad Argentina de Antropología VII: 87-122.

Cardich, Augusto, Rafael Paunero y Alicia Castro

1994 «Análisis de los conjuntos líticos de la Cueva 2 de Los Toldos (Santa Cruz, Argentina)». Anales del Instituto de la Patagonia 22: 149-173.

Cassiodoro, G., D. Rindel, R. Goñi, A. Re, A. Tessone, S. García Guraieb, J. Belardi, S. Espinosa, A. Nuevo Delaunay, J. Dellepiane, J. Flores Coni, F. Guichón, C. Martinez y S. PASQUALINI

2013 «Arqueología del Holoceno Medio y Tardío en Patagonia Meridional: poblamiento humano y fluctuaciones climáticas». Diálogo Andino 41: 5-23. 
Cassiodoro, Gisela, Silvana Espinosa, Josefina Flores Coni y Rafael GoÑI

2015 «Disponibilidad de recursos líticos y movilidad durante el Holoceno Tardío en el centro-oeste de la provincia de Santa Cruz». Intersecciones en Antropología 2: 75 86.

Cattáneo, G. Roxana

2004 «Desarrollo metodológico para el estudio de fuentes de aprovisionamiento lítico en la Meseta Central Santacruceña, Patagonia Argentina». Estudios Atacameños 28: 105-119.

DURÁN, Víctor

1990 «Estudio tecno-tipológico de los raspadores del sitio El Verano. Cueva 1 (Área de La Martita). Provincia de Santa Cruz». Anales de Arqueología y Etnología 41-42: 129-163.

DuRÁN, Víctor, Adolfo GIL, Gustavo Neme y Alejandra Gasco

2003 «El Verano: ocupaciones de 8900 años en la Cueva 1 (Santa Cruz, Argentina)», en Arqueología y paleoambiente en la Patagonia Santacruceña Argentina, Ana Aguerre, comp., pp. 93-120. Buenos Aires: Edición del autor.

FRANCO, Nora

2002 «Es posible diferenciar los conjuntos líticos atribuidos a la exploración de un espacio de los correspondientes a otras etapas del poblamiento?» Werken 3: 119-132.

Franco, Nora, Pablo Ambrústolo, Marilina Martucci, George BrooK, Ma. Virginia MaNCINI y Natalia CirigLiano

2010 «Early Human Occupation in the Southern Part of the Deseado Massif Patagonia, Argentina)». Current Research in the Pleistocene 27: 13-16.

Franco, Nora, Pablo Ambrústolo y Natalia Cirigliano

2012 «Disponibilidad de materias primas líticas silíceas en el extremo sur del Macizo del Deseado: los casos de La Gruta y Viuda Quenzana (Provincia de Santa Cruz, Argentina)». Magallania 40 (1): 279-286.

GoÑI, Rafael

2010 Cambio climático y poblamiento humano durante el Holoceno Tardio en Patagonia Meridional. Una perspectiva arqueológica. Tesis de doctorado. Universidad de Buenos Aires. Ms

GurÁIEB, Ana Gabriela

1999 «Análisis de la diversidad en los conjuntos instrumentales líticos de Cerro de los Indios I (Lago Posadas, Santa Cruz)». Relaciones de la Sociedad Argentina de Antropología 24: 293-306.

Hermo, Darío

2008 Los cambios en la circulación de las materias primas líticas en ambientes mesetarios de Patagonia. Una aproximación para la construcción de los paisajes arqueológicos de las sociedades cazadoras-recolectoras. Tesis doctoral de la Facultad de Ciencias Naturales Universidad Nacional de La Plata. La Plata.

2009 «Estructura de los recursos líticos y paisajes arqueológicos en el Nesocratón del Deseado (Santa Cruz, Argentina)». Arqueología Suramericana/Arqueología Sulamericana 5 (2): 178-203. 
Hermo, Darío y Virginia LYNCH

2015 «Core Technology from Maripe Cave Site (Santa Cruz, Argentina): Implications for Rocks Provisioning Processes and Lithic Production». Quaternary International 375: 135-144.

Hermo, Darío y Lucía MAGNin

2012 «Blade and Bifacial Technology in Mid-Holocene Occupations at Deseado Massif, Santa Cruz Province, Argentina». Quaternary International 256: 71-77.

Hermo, Darío y Laura Miotti

2011 «La obsidiana en el Nesocratón del Deseado (Santa Cruz, Argentina): extractos de una oscura biografía», en Biografías de paisajes y seres. Visiones desde la arqueología sudamericana, Darío Hermo y Laura Miotti, eds., pp. 111-131. Córdoba: Encuentro Grupo Editor.

Hermo, Darío, Lucía Magnin, Pilar Moreira y Santiago Medel

2015 «Variabilidad y distribución de fuentes de materias primas líticas en el Macizo del Deseado (Santa Cruz, Argentina)». Intersecciones en Antropología 16 (1): 87-100.

LYNCH, Virginia

2013 «Análisis morfológico-funcional de raspadores líticos del sitio Cueva Maripe (Santa Cruz, Argentina)», en Tendencias teórico-metodológicas y casos de estudio en la arqueología de Patagonia, Francisco Zangrando et al., eds., pp. 406-416. Buenos Aires: Sociedad Argentina de Antropología, INALP, Museo de Historia Natural de San Rafael.

2014 Estudio comparativo de la producción y uso de artefactos líticos en el Macizo del Deseado (Santa Cruz, Argentina).Tesis doctoral. Facultad de Ciencias Naturales y Museo, Universidad Nacional de La Plata.

LYNCH, Virginia y Darío HeRmo

2015 «Evidence of Hafting Traces on Lithics End-Scrapers at Maripe Cave Site (Santa Cruz, Argentina)». Lithic Technology 40 (1): 68-79.

LYNCH, Virginia y Laura MiotTI

2016 «Morphological and Functional Variability on the End-Scrapers in Cueva Maripe Site (Santa Cruz Province, Argentina)». Lithic Technology 41 (1): 60-74.

Magnin, Lucía

2015 «Hunter-Gatherer Provisioning Strategies in a Landscape with Abundant Lithic Resources (La Primavera, Santa Cruz, Argentina)». Quaternary International 375: 55 71.

Mancini, Ma Virginia, Nora Franco y George Brook

2013 «Palaeoenvironment and Early Human Occupation of Southernmost South America (South Patagonia, Argentina)». Quaternary International 299: 13-22.

Mansur-Franchome, $M^{\text {a }}$ Estela

1983 Traces d'utilisation et technologie lithique: examples de la Patagonie. Tesis de 3er Ciclo, $\mathrm{N}^{\circ} 1860$. Université de Bordeaux I.

MARCHIONNI, Laura

2013 Comparación de las distintas historias tafonómicas en conjuntos zooarqueológicos provenientes de la Meseta Central de la provincia de Santa Cruz. Tesis doctoral. Facultad de Ciencias Naturales y Museo, Universidad Nacional de La Plata. 
MiotTi, Laura

1995 «Piedra Museo Locality: A Special Place in the New World». Current Research in the Pleistocene 12: 36-38.

1998 Zooarqueología de la meseta central y la costa de la provincia de Santa Cruz. Un enfoque de las estrategias adaptativas y los paleoambientes. San Rafael: Museo de Ciencias Naturales de San Rafael.

2006 «Paisajes domésticos y sagrados desde la arqueología de los cazadores- recolectores en el Macizo del Deseado, provincia de Santa Cruz». Cazadores Recolectores del Cono Sur. Revista de Arqueología 1: 13-42,

2012 «El uso de los recursos faunísticos entre los cazadores-recolectores de Patagonia: tendencias espacio/temporales de las estrategias durante el Holoceno». Archeofauna 21: 137-162.

Miotti, Laura y Mónica SALemme

1999 «Biodiversity, Taxonomic Richness and Specialists-Generalists during Late Pleistocene/Early Holocene Times in Pampa and Patagonia (Argentina, Southern South America)». Quaternary International 53-54: 53-68.

2004 «Poblamiento, movilidad y territorios entre las sociedades cazadoras-recolectoras de Patagonia». Complutum 15: 177-206.

Miotti, Laura, Martín VÁzquez y Darío Hermo

1999 «Piedra Museo: un yamnagoo pleistocénico de los colonizadores de la Meseta de Santa Cruz. El estudio de la arqueofauna», en Soplando en el Viento. Actas de las III Jornadas de Arqueología de la Patagonia, pp.113-136. Neuquén-Buenos Aires: Universidad Nacional del Comahue e Instituto Nacional de Antropología y Pensamiento Latinoamericano.

Miotti, Laura, Darío Hermo, Lucía Magnín, Natalia Carden, Bruno Mosquera, Enrique Terranova, Laura Marchionni y Mónica Salemme

2007 «Resolución e integridad arqueológica en la Cueva Maripe (Santa Cruz, Argentina)», en Arqueología de Fuego-Patagonia. Levantando piedras, desenterrando huesos... y develando arcanos, F. Morello, M. Martinic, A. Prieto y G. Bahamonde, eds., pp. 555-568. Punta Arenas: CEQUA.

Miotti, Laura, Laura Marchionni, Bruno Mosquera, Darío Hermo y Antonio Ceraso

2014 «Fechados radiocarbónicos y delimitación temporal de los conjuntos arqueológicos de Cueva Maripe, Santa Cruz (Argentina)». Relaciones de la Sociedad Argentina de Antropología XXXIX (2): 509-537.

Miotti, Laura, Darío Hermo, Enrique Terranova y Rocío Blanco

2015 «Edenes en el desierto. Señales de caminos y lugares en la historia de la colonización de Patagonia argentina». Antípoda. Revista de Antropología y Arqueología 23: 161-185.

Mosquera, Bruno

2014 «Análisis geoarqueológico del sitio Cueva Maripe, Macizo del Deseado (Santa Cruz, Argentina): primeros resultados», en Entre pasados y presentes IV. Estudios contemporáneos en Ciencias Antropológicas, Analía Castro et al., eds., pp. 641660. Buenos Aires: Asociación de Amigos del Instituto Nacional de Antropología.

NAMI, Hugo

2003 «Experimentos para explorar la secuencia de reducción Fell de la Patagonia Austral». Magallania 30: 107-138. 
NELSON, Margaret

1991 «The Study of Technological Organization», en Archaeological Method and Theory, Vol. 3, Michael B. Schiffer, ed., pp. 57-100. Tucson: University of Arizona Press.

ORQUERA, Luis

1984-85 «Tradiciones culturales y evolución en Patagonia». Relaciones de la Sociedad Argentina de Antropología 16: 249-267.

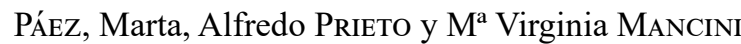

1999 «Fossil Pollen from Los Toldos Locality: A Record of the Late-Glacial Transition in the Extra-Andean Patagonia». Quaternary International 53-54: 69-75.

PAUNERo, Rafael

2003 «The Presence of a Pleistocenic Colonizing Culture in La Maria Archaeological Locality: Casa del Minero 1, Argentina», en Where the South Winds Blow, L. Miotti, M. Salemme y N. Flegenheimer, eds., pp. 127-132. College Station: Center for the Study of First Americans, Texas A\&M University Press.

Paunero, Rafael y Alicia CASTro

2001 «Análisis lítico y funcionalidad del componente inferior del sitio Cueva 1, localidad arqueológica Cerro Tres Tetas, Provincia de Santa Cruz, Argentina». Anales del Instituto de la Patagonia (Serie Ciencias Sociales) 29: 189-206.

Paunero, Rafael, Alicia CAstro y Mariano Reyes

2007 «Estudios líticos del componente medio del Sitio Cueva 1 de cerro Tres Tetas, Santa Cruz, Argentina: implicaciones para construir patrones de distribución artefactual y uso del microespacio», en Arqueología de Fuego-Patagonia. Levantando piedras, desenterrando huesos... y develando arcanos, F. Morello, A. Prieto, M. Martinic y G. Bahamonde, eds., pp. 613-622. Punta Arenas: Centro de Estudios del Cuaternario Antártico (CEQUA).

PiELOU, Evelyn

1977 Mathematical Ecology. Nueva York: John Wiley and Sons.

Salemme Mónica y Laura Miotti

2008 «Archaeological Hunter-Gatherer Landscapes since the Latest Pleistocene in Fuego-Patagonia», en The Late Cenozoic of Patagonia and Tierra del Fuego, Vol. 11, Jorge Rabassa, ed., pp. 437-483. Amsterdam: Elsevier.

SHANNON, Claude y Warren WeAVER

1949 The Mathematical Theory of Communication. Urbana: The University of Illinois Press.

SKARBUn, Fabiana

2011 La organización tecnológica en grupos cazadores recolectores desde las ocupaciones del Pleistoceno final al Holoceno tardio, en la Meseta Central de Santa Cruz, Patagonia. Oxford: BAR International Series 2307.

Skarbun, Fabiana, Manuel Cueto, Ariel Frank y Rafael Paunero

2015 «Producción, consumo y espacialidad en Cueva Túnel, meseta central de Santa Cruz, Argentina». Chungará 47 (1): 85-99.

STERn, Charles

1999 «Black Obsidian from Central-South Patagonia; Chemical Characteristics, Sources and Regional Distribution of Artifacts», en Soplando en el Viento. Actas de las III Jornadas de Arqueología de la Patagonia, Vol. 1, pp. 221-234. Neuquén-Buenos 
Aires: Universidad Nacional del Comahue e Instituto Nacional de Antropología y Pensamiento Latinoamericano.

ZAR, Jerrold

1974 Biostatistical Analysis. Upper Saddle River: Prentice Hall.

ZÁRATE, Marcelo, Adriana Blassi y Jorge RABASSA

2000 «Geoarqueología de la localidad Piedra Museo», en Guía de Campo de la Visita a las Localidades Arqueológicas. Taller Internacional del INQUA La Colonización del Sur de América Durante la Transición Pleistoceno/Holoceno, L. Miotti, R. Paunero, M. Salemme y G. Cattáneo, eds., pp. 56-64. La Plata: Imprenta Servicoop. 